\title{
N6-(2-hydroxyethyl)-Adenosine Induces Apoptosis via ER Stress and Autophagy of Gastric Carcinoma Cells In Vitro and In Vivo
}

\author{
Hongqing Xie ${ }^{1}$, Xiaotong $\mathrm{Li}^{1}{ }^{1}$ ) , Weiwei Yang ${ }^{2}$, Liping $\mathrm{Yu}^{2}$, Xiasen Jiang ${ }^{1}$, Yajie Chen ${ }^{1}$, \\ Zhangfei Shen ${ }^{1}$, Conghui $\mathrm{Li}^{1}{ }^{1}$, Meier $\mathrm{Gu}^{2, *}$ and Liangen Shi ${ }^{1, * \mathbb{D}}$ \\ 1 College of Animal Sciences, Zhejiang University, Hangzhou 310058, China; xiehongqing@zju.edu.cn (H.X.); \\ lixiaotong@zju.edu.cn (X.L.); jxsen@zju.edu.cn (X.J.); yajiesw@126.com (Y.C.); szf@zju.edu.cn (Z.S.); \\ lch941114@163.com (C.L.) \\ 2 Laboratory Animal Center, Hangzhou Normal University, Hangzhou 311121, China; \\ dwzxyww@163.com (W.Y.); ylp1975@hznu.edu.cn (L.Y.) \\ * Correspondence: gme0321@hznu.edu.cn (M.G.); slgsilk@zju.edu.cn (L.S.); Tel.: +86-0571-88982723 (L.S.)
}

Received: 14 July 2020; Accepted: 10 August 2020; Published: 13 August 2020

\begin{abstract}
Gastric cancer is the most common malignant tumor of the digestive tract and is great challenge in clinical treatment. N6-(2-Hydroxyethyl)-adenosine (HEA), widely present in various fungi, is a natural adenosine derivative with many biological and pharmacological activities. Here, we assessed the antineoplastic effect of HEA on gastric carcinoma. HEA exerted cytotoxic effects against gastric carcinoma cells (SGC-7901 and AGS) in a dose and time-dependent manner. Additionally, we found that HEA induced reactive oxygen species production and mitochondrial membrane potential depolarization. Moreover, it could trigger caspase-dependent apoptosis, promoting intracellular $\mathrm{Ca}^{2+}$-related endoplasmic reticulum (ER) stress and autophagy. On the other hand, HEA could significantly inhibit the growth of transplanted tumors in nude mice and induce apoptosis of tumor tissues cells in vivo. In conclusion, HEA induced apoptosis of gastric carcinoma cells in vitro and in vivo, demonstrating that HEA is a potential chemotherapeutic agent for gastric carcinoma.
\end{abstract}

Keywords: N6-(2-Hydroxyethyl)-adenosine; apoptosis; endoplasmic reticulum stress; gastric carcinoma; autophagy

\section{Introduction}

Gastric cancer is a malignant tumor originating from gastric mucosal epithelium; it is the fifth most common cancer (with 951,000 new cases per year) and has the third lowest survival rate (754,000 deaths each year worldwide, of which more than $70 \%$ occur in developing countries) [1,2]. Surgery is the main treatment option for gastric carcinoma, and adjuvant therapy should also be considered. The five-year survival rate of patients receiving chemotherapy was found to improve by $11 \%$ after surgery [3]. In Europe, the preferred treatment scheme for gastric carcinoma is perioperative chemotherapy with epirubicin, cisplatin, or fluorouracil (5-FU) [4]. However, chemoradiotherapy-associated acute toxicity should also be given attention. To study the efficacy of adjuvant therapy after surgery, a controlled trial involving 556 patients with gastric carcinoma revealed that chemoradiotherapy could remarkably improve survival rate and prolong survival time; however, three patients (1\%) died from the toxicity of chemoradiotherapy, $41 \%$ of the chemoradiotherapy group had grade 3 toxicity, and $32 \%$ had grade 4 toxic effects [3]. Therefore, it is necessary to search for effective chemotherapeutic agents for gastric carcinoma with less side effects.

Various fungi of Cordyceps species have anticancer activities [5]. As one of the main biological components of Cordyceps species, N6-(2-Hydroxyethyl)-adenosine (HEA) was first isolated from 
Cordyceps and Isaria species in 1983 (structure is shown in Figure 1). The separation and preparation of HEA have been reported [6,7]. Pharmacological studies found that HEA possesses antihyperglycemic, kidney protective, antioxidant, sedative, anti-inflammatory, and myocardium protective effects and interacts with human serum albumin [8-12].

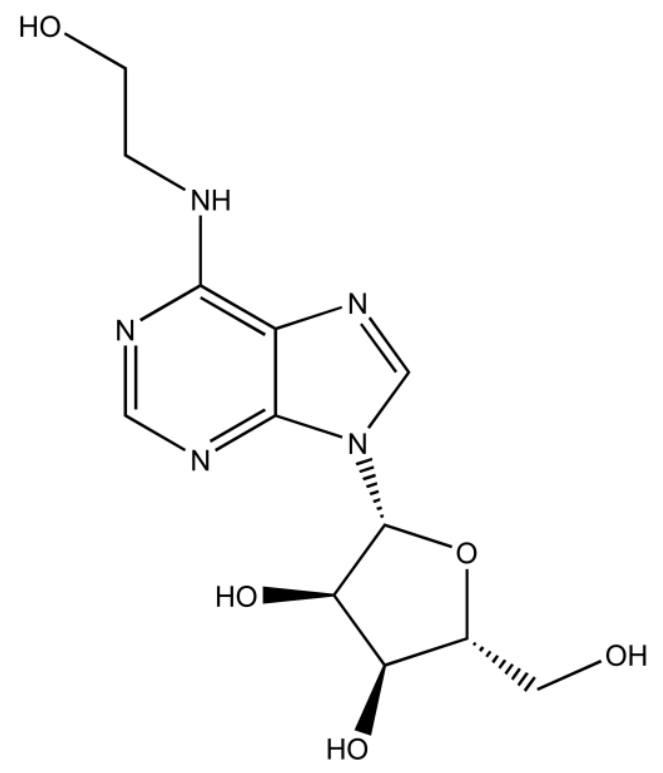

N6-(2-hydroxyethyl)-adenosine

molecular formula: $\mathrm{C}_{12} \mathrm{H}_{17} \mathrm{~N}_{5} \mathrm{O} 5$

molecular weight: $311.29 \mathrm{~g} / \mathrm{mol}$

Figure 1. Chemical structure of HEA. The molecular formula of HEA is $\mathrm{C}_{12} \mathrm{H}_{17} \mathrm{~N}_{5} \mathrm{O}_{5}$, and the molecular weight is $311.29 \mathrm{~g} / \mathrm{mol}$.

The identification of active ingredients and the verification of the pharmacological actions of natural products are the current research trends. Previous studies have shown that the ethanolic extract of C. cicadae (EEC) has antitumor effects in vitro, and HEA is one of the main components of EEC [13]. In recent years, a few studies have investigated the antitumor effects of HEA, but its efficacy and mechanism are still unclear [14]. Chronic inflammation is one of the precipitating factors of tumorigenesis. Additionally, the inhibition of NF- $\mathrm{kB}$ signal can lead to apoptosis of transformed hepatocytes and failure to develop into hepatocellular cancer [15]. Moreover, TGF- $\beta$ protein induces apoptosis and cell cycle arrest in the early stage of tumorigenesis. However, with the development of tumors, increased levels of TGF- $\beta$ promote tumorigenesis by stimulating immune system migration, invasion, angiogenesis, and escape [16]. HEA can regulate the NF- $\mathrm{KB}$ and TGF- $\beta$ signaling pathways in vivo and in vitro and inhibit the production of IL-1 $\beta, T N F-\alpha$, prostaglandin $E_{2}$, and cyclooxygenase- 2 to exert anti-inflammatory effects $[10,17]$. These findings suggest that HEA may be an ideal candidate for cancer chemotherapy. It is worthwhile to study the anticancer potentiality of HEA.

In this work, we demonstrated that HEA inhibited the proliferation of gastric carcinoma in vitro and in vivo for the first time. Mechanism studies showed that HEA induced ER stress and autophagy-mediated apoptosis in vitro. HEA inhibited the growth of SGC-7901-infected tumors and induced the apoptosis of tumor tissues in nude mice. These results suggested that HEA may become a chemotherapeutic agent for gastric carcinoma. 


\section{Results}

\subsection{HEA Induced Cytotoxicity Effects in Gastric Carcinoma Cells}

Previous studies have shown that the EEC has a lower $\mathrm{IC}_{50}$ value for gastric carcinoma SGC-7901 cells than for lung cancer H1299 cells, hepatocellular carcinoma HepG2 cells, lung carcinoma A549 cells, and cervical cancer HeLa cells [13]. To verify whether HEA is the major anti-gastric cancer compound in EEC, we used the gastric cancer cell lines SGC-7901 and AGS as the target cancer cell lines, and used HEK293 cells used in EEC research as the normal cell line. We investigated the toxicity of HEA in gastric carcinoma cell lines SGC-7901 and AGS, and human embryonic kidney cell line HEK293. The results showed that HEA exerted cytotoxic effects against SGC-7901 and AGS cells in a dose and time-dependent manner (Figure 2A,B and Figure S1). We calculated that the $\mathrm{IC}_{50}$ value of HEA against SGC-7901 cells was $86.66 \mu \mathrm{M}$, and the $\mathrm{IC}_{50}$ value of HEA against AGS cells was $94.46 \mu \mathrm{M}$. These findings suggest that HEA exerted cytotoxic effects against gastric carcinoma cells. By contrast, HEA had no significant toxicity to HEK293 cells until its dose reached $250 \mu \mathrm{M}$, demonstrating the toxicity of HEA for gastric carcinoma cells over normal cells (Figure 2A).

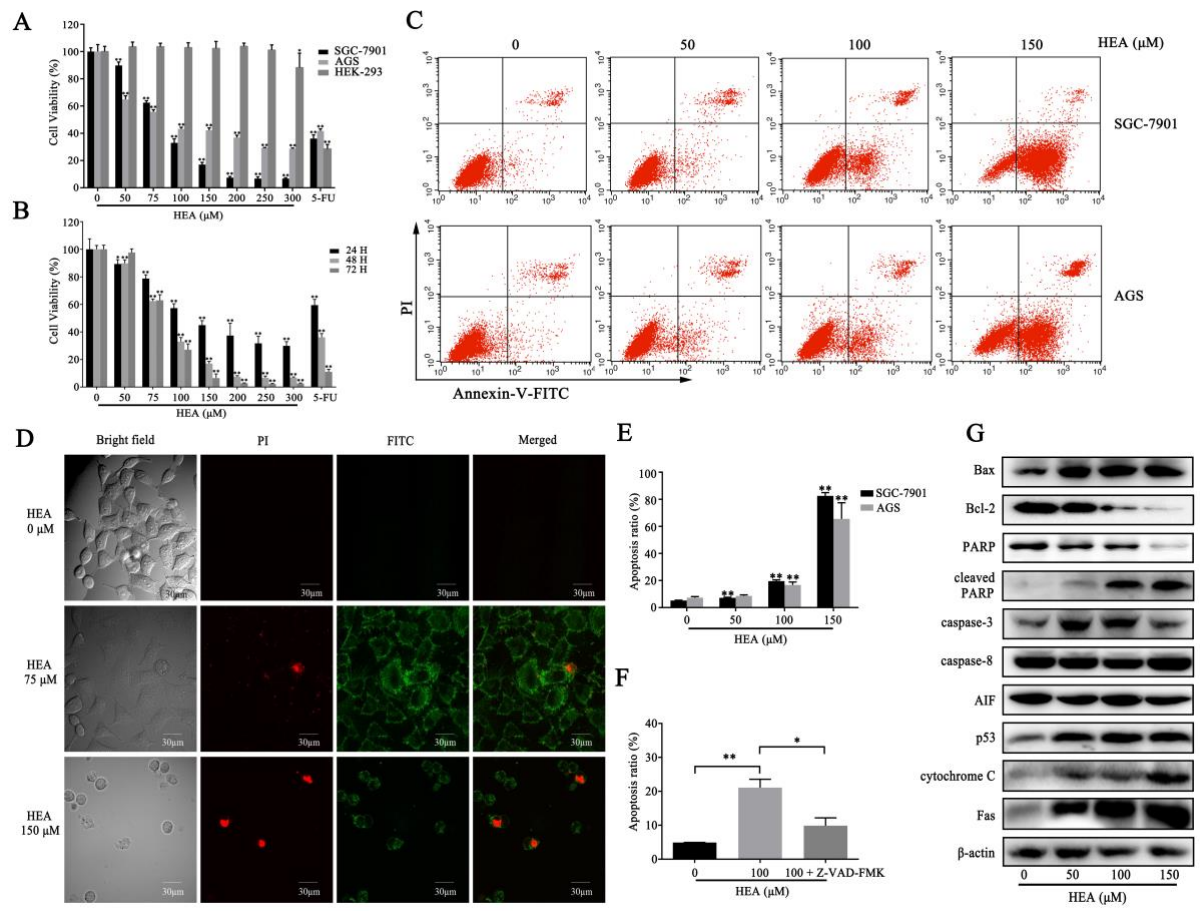

Figure 2. HEA induced inhibitory effects in gastric carcinoma cells. (A) Estimation of cytotoxicity using CCK-8 assay with various doses of HEA in SGC-7901, AGS, and HEK293 cells. The cells (SGC-7901, AGS, and HEK293) were treated with 0, 50, 75, 100, 150, 200, 250, and $300 \mu \mathrm{M} \mathrm{HEA}$ and $20 \mu \mathrm{g} \cdot \mathrm{mL}^{-1}$ 5-FU for $48 \mathrm{~h}$ and were then detected using CCK-8 assay, with five repeats per group. (B) Evaluation of cytotoxicity using CCK-8 assay with various doses of HEA at different treatment times in SGC-7901 cells. SGC-7901 cells were treated with HEA and 5-FU for 24, 48, and $72 \mathrm{~h}$ and were then evaluated for cell viability, with five repeats per group. (C) HEA promoted apoptosis of gastric carcinoma SGC-7901 and AGS cells. SGC-7901 and AGS cells were incubated with $\operatorname{HEA}(0,50,100$, and $150 \mu \mathrm{M})$ for $48 \mathrm{~h}$, and apoptosis level was detected via Annexin V-FITC/PI assay. (D) Apoptosis level changes in SGC-7901 cells detected by a laser confocal microscope after Annexin V-FITC/PI staining. (E) Columns for SGC-7901 and AGS apoptosis levels when incubated with $\operatorname{HEA}(0,50,100$, and $150 \mu \mathrm{M})$. (F) Columns for apoptotic SGC-7901 cells incubated with vehicle, HEA $(100 \mu \mathrm{M})$, and HEA $(100 \mu \mathrm{M})+$ Z-VAD-FMK $(20 \mu \mathrm{M}) .(\mathrm{G})$ Effect of HEA on protein apoptosis in relation to SGC-7901 cells. Cells were treated with HEA $(0,50,100$, and $150 \mu \mathrm{M})$, and proteins were extracted for Western blot analysis. ${ }^{* *} p<0.01$, * $p<0.05$ compared with $0 \mu \mathrm{M}$ HEA group, three repeats per group. 


\subsection{HEA Promoted Apoptosis in Gastric Carcinoma SGC-7901 and AGS Cells}

To determine the apoptotic effect induced by HEA, we performed an Annexin V-FITC/PI assay using flow cytometry, and a laser confocal microscope was used for observation after Annexin V/PI staining. The total percentages of apoptotic SGC-7901 cells were $5.22 \% \pm 0.07 \%$ for the control group, $7.17 \% \pm 0.20 \%$ for the HEA $50 \mu \mathrm{M}$ group, $19.58 \% \pm 0.79 \%$ for the HEA $100 \mu \mathrm{M}$ group, and $82.51 \% \pm 6.09 \%$ for the HEA $150 \mu \mathrm{M}$ group. The total percentages of apoptotic AGS cells were $7.26 \% \pm 0.89 \%$ for the control group, $8.59 \% \pm 0.76 \%$ for the HEA $50 \mu \mathrm{M}$ group, $16.73 \% \pm 2.15 \%$ for the HEA $100 \mu \mathrm{M}$ group, and $65.54 \% \pm 11.89 \%$ for the HEA $150 \mu \mathrm{M}$ group. HEA enhanced the apoptotic rate in SGC-7901 and AGS cells (Figure 2C,E). Changes in fluorescence after Annexin V-FITC/PI staining showed that the $75 \mu \mathrm{M}$ HEA group exhibited a significant increase in green fluorescence, which is a typical morphological characteristic of early apoptosis (Figure 2D). The cells treated with $150 \mu \mathrm{M}$ HEA exhibited increased red fluorescence, indicating that the late apoptotic rate of cells increased (Figure 2D). Treatment with 75 and $150 \mu$ M HEA reduced the number of cells, suggesting that the cells may have detached from the plate. Thereafter, we detected the expression level of apoptotic key regulators. The expression level of proapoptotic protein Bax was significantly increased, and the expression of antiapoptotic regulator Bcl-2 was decreased. Moreover, HEA upregulated the expression of caspase-3, caspase-8, p53, cytochrome C, and Fas, and PARP was cleaved (Figure 2G), which may have promoted apoptosis. Pretreatment with $20 \mu \mathrm{M}$ caspase inhibitor (Z-VAD-FMK) effectively mitigated the apoptosis induced by HEA (Figure 2F), confirming that caspases played a role in regulating HEA-induced apoptosis.

\subsection{HEA Induced ROS Production and MMP Depolarization of Gastric Carcinoma SGC-7901 Cells}

The production of ROS leads to mitochondrial dysfunction and DNA damage, which leads to cell apoptosis $[18,19]$. MMP loss is a characteristic manifestation of mitochondrial dysfunction and plays a significant role in apoptosis [20]. To determine whether the apoptosis-regulating effect of HEA was related to mitochondrial dysfunction, flow cytometry was used to measure the changes in cellular ROS and MMP after HEA treatment. The results showed that HEA could significantly increase ROS production and decrease MMP (Figure 3), suggesting that HEA-induced apoptosis may be related to mitochondrial dysfunction.

\subsection{HEA Elevated Intracellular $\mathrm{Ca}^{2+}$ Levels, Leading to ER Stress-Mediated Apoptosis in Gastric Carcinoma} SGC-7901 Cells

ER stress is characterized by misfolding of the ER lumen and disturbance of $\mathrm{Ca}^{2+}$ balance. Upregulation of ER chaperone proteins such as glucose regulatory protein 78 (GRP78) can activate the apoptotic pathways mediated by caspase-12. A Fluo-3 AM fluorescence probe was used to detect the relative changes of intracellular $\mathrm{Ca}^{2+}$ level after treatment with various doses of HEA in SGC-7901 cells, and Western blot analysis was used to detect the expression changes of ER stress-related proteins. HEA treatment resulted in a significant increase in fluorescence intensity, indicating a significant increase in intracellular $\mathrm{Ca}^{2+}$ concentration in SGC-7901 cells (Figure 4A,B). Moreover, the protein expression levels of ATF-4, CHOP, GRP78, caspase-12, and caspase-9 increased in the HEA-treated group, suggesting that HEA may have induced ER stress and activated the caspase-12-mediated apoptotic pathway (Figure 4C). The co-addition of 4-PBA (an ER stress inhibitor, $1 \mathrm{mM}$ ) and HEA further confirmed the role of ER stress in HEA-induced apoptosis. In SGC-7901 cells, the apoptotic rate of co-treated cells was significantly decreased compared to cells treated with HEA only, suggesting that the inhibition of ER stress weakened the apoptotic effect of HEA (Figure 4D). 
A
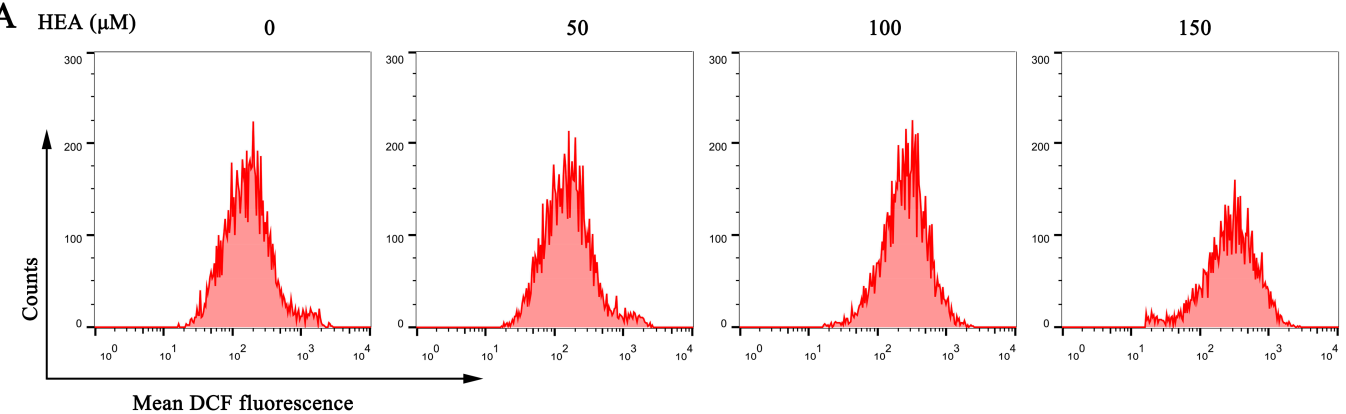

B
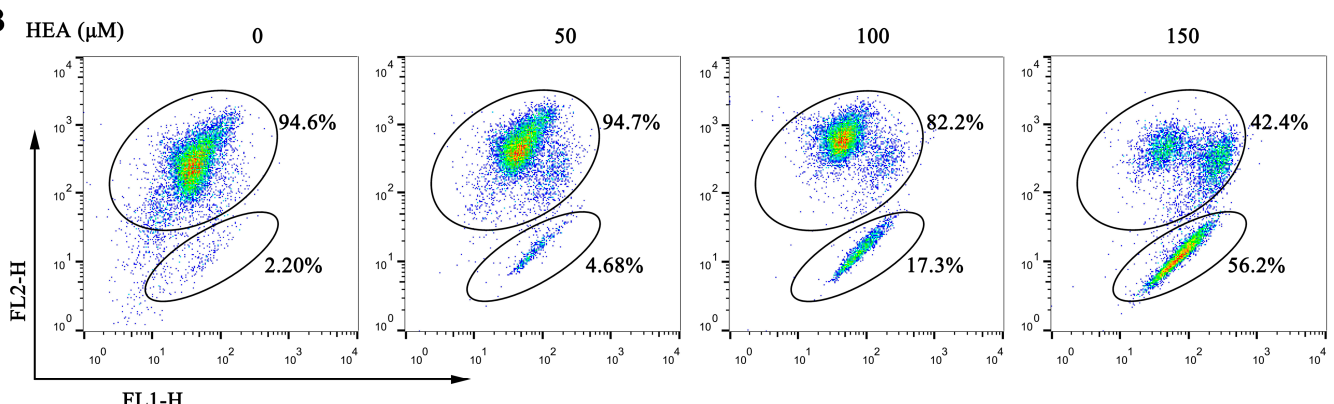

C

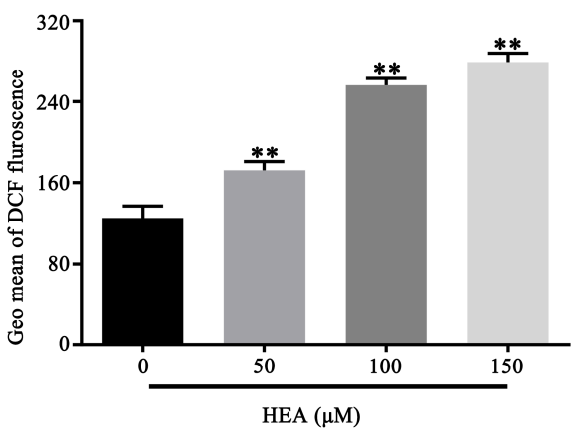

D

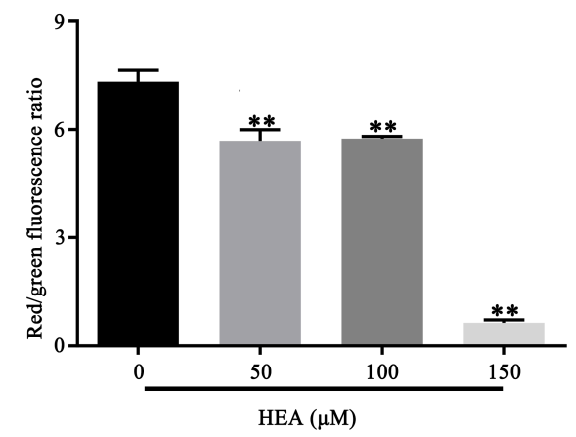

Figure 3. HEA induces ROS production and MMP reduction of SGC-7901 cells. (A) After treatment with HEA for 48 h, SGC-7901 cells were stained with ROS indicator (DCF-DA). (B) MMP measurement of SGC-7901 cells using JC-1 probe by flow cytometry. (C) Quantitation of average DCF fluorescence, indicated by Geo Mean. (D) Histograms of average fluorescence intensity. ${ }^{* *} p<0.01$ compared with $0 \mu \mathrm{M}$ HEA group, three repeats per group.

\subsection{HEA Promoted Autophagy-Mediated Apoptosis of SGC-7901 Cells}

Autophagy was observed by TEM, and the expression of autophagy-related proteins was detected to evaluate whether autophagy occurred in SGC-7901 after treatment with HEA. The results of TEM showed that autophagosomes with a typical multimembrane structure appeared after HEA treatment, and autolysosome appeared in $100 \mu \mathrm{M}$ HEA group and $150 \mu \mathrm{M}$ HEA group (Figure 5A). Western blot analysis of autophagy-related proteins showed that the expression of LC3-II increased remarkably, and the ratio of LC3-II to LC3-I showed a tendency to increase after HEA treatment. We observed upregulations in ATG5, ATG12, and Beclin1 expressions and a downregulation in p62 expression, indicating that HEA-induced autophagy mediated apoptosis in SGC-7901 cells (Figure 5B). However, ATG12, and Beclin1 were down regulated at $150 \mu \mathrm{M}$, which may be related to the combination of ATG12 or Beclin1 with Bcl-2 domain to regulate apoptosis [21,22]. Moreover, the co-addition of 3-MA (an autophagy inhibitor, $5 \mathrm{mM}$ ) and HEA further confirmed the role of autophagy in HEA-induced apoptosis. In SGC-7901 cells, the apoptotic induction of co-treated cells was significantly lesser than for cells treated with HEA only, suggesting that the inhibition of autophagy weakened the proapoptotic effect of HEA (Figure 5C). 
A

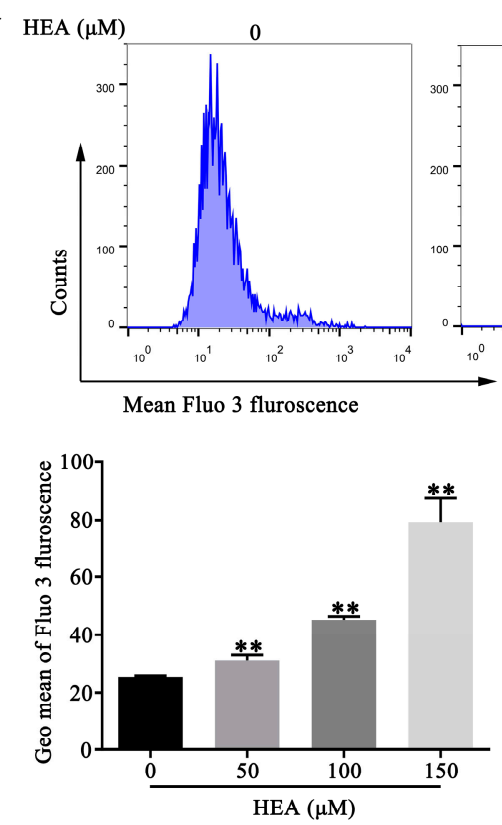

50

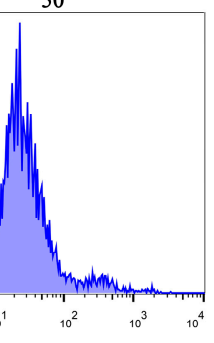

C

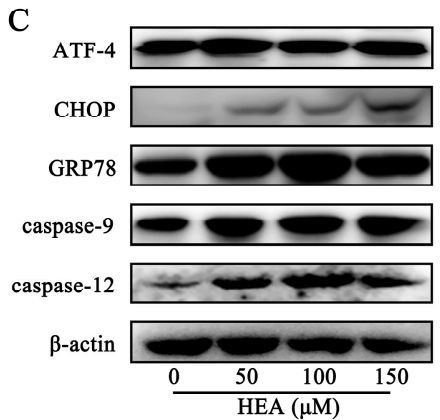

100
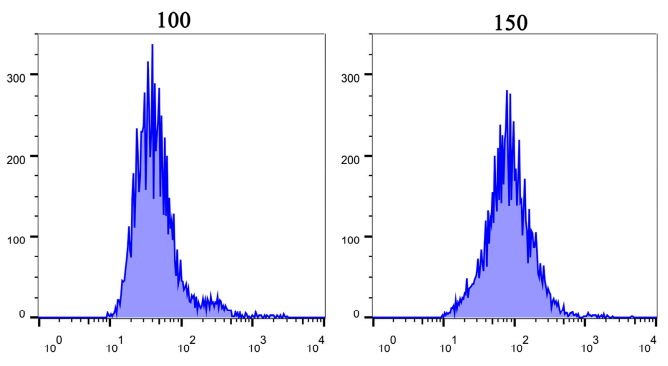

D

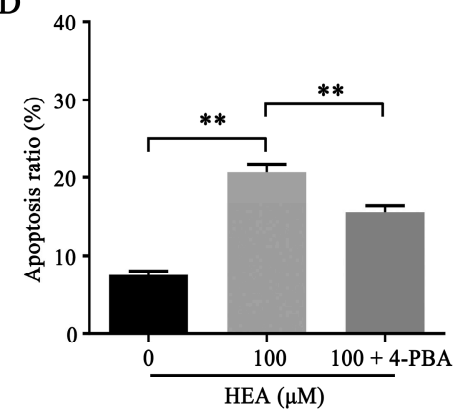

Figure 4. HEA-induced ER stress of SGC-7901 cells. (A) Cells were treated with HEA for $48 \mathrm{~h}$, and intracellular $\mathrm{Ca}^{2+}$ was measured using Fluo-3 AM probe. (B) Histogram of average Fluo-3 AM, indicated by Geo Mean. (C) Western blot analysis of HEA on the expressions of ER stress-related proteins. (D) Columns for apoptotic SGC-7901 cells incubated with vehicle, HEA (100 $\mu$ M), HEA $(100 \mu \mathrm{M})+4$-PBA $(1 \mathrm{mM})$, and ER stress inhibitor 4-PBA and HEA had those compounds added $48 \mathrm{~h}$ before the apoptosis detection assay. ${ }^{* *} p<0.01$ compared with $0 \mu \mathrm{M}$ HEA group, three repeats per group.

A

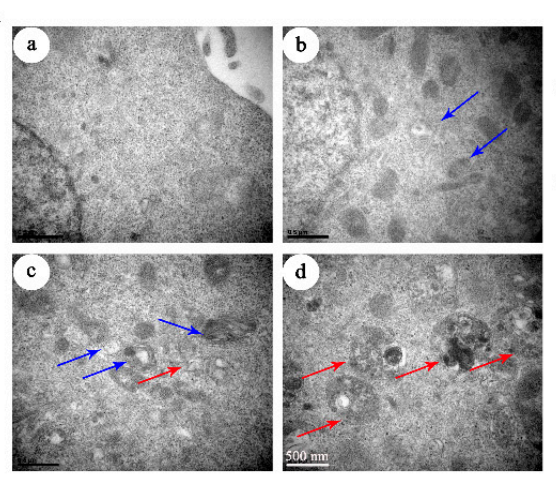

B

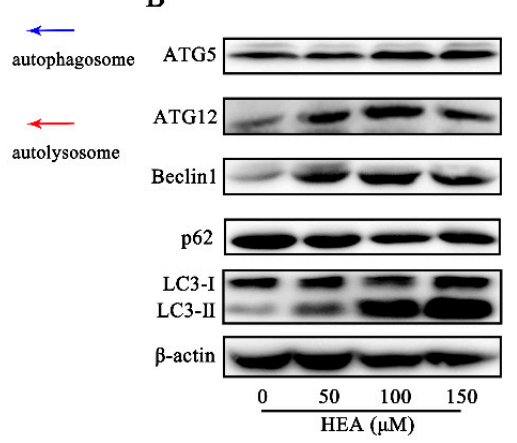

C

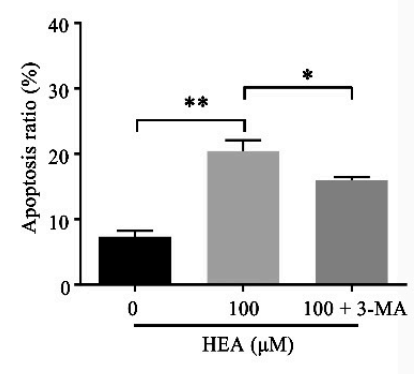

Figure 5. HEA-induced autophagy of SGC-7901 cells. (A) Representative TEM for SGC-7901 cells incubated with the following doses of HEA: (a) 0, (b) 50, (c) 100, and (d) $150 \mu \mathrm{M}$; blue arrows represent autophagosome, and red arrows represent autolysosome. (B) Expression levels of ATG5, ATG12, Beclin1, p62, and LC3 in SGC-7901 cells after treatment with HEA for $48 \mathrm{~h}$ by immunoblotting. (C) Columns for apoptotic SGC-7901 cells incubated with vehicle, HEA $(100 \mu \mathrm{M})$, HEA $(100 \mu \mathrm{M})+3-\mathrm{MA}(5 \mathrm{mM})$, and autophagy inhibitor 3-MA and HEA had those compounds added $48 \mathrm{~h}$ before the apoptosis detection assay. ${ }^{* *} p<0.01,{ }^{*} p<0.05$ compared with $0 \mu \mathrm{M}$ HEA group, three repeats per group.

\subsection{Inhibition of Tumor Growth by HEA in a Gastric Carcinoma Nude Mouse Model in Vivo}

We injected female BALB/c nude mice with $2 \times 10^{6}$ SGC-7901 cells and intragastrically administered HEA to detect the antitumor activity of HEA in vivo. Compared with the vehicle group, HEA gavage caused a reduction in tumor size (Figure 6A), tumor volume, and tumor weight in a dose-dependent manner; $75 \mathrm{mg} / \mathrm{kg}$ of HEA showed an effect similar to that of 5-FU (Figure 6B,C). After 19 days of 
intragastric administration, $75 \mathrm{mg} / \mathrm{kg}$ of HEA resulted in an inhibition rate of $54.66 \%$, and $100 \mathrm{mg} / \mathrm{kg}$ of HEA exhibited an inhibition rate of $64.90 \%$ (Figure 6D). Treatment with HEA did not result in significant weight loss during the whole course of administration (Figure S2).

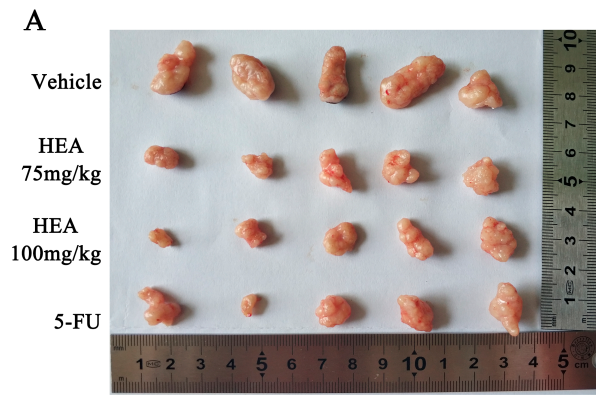

D

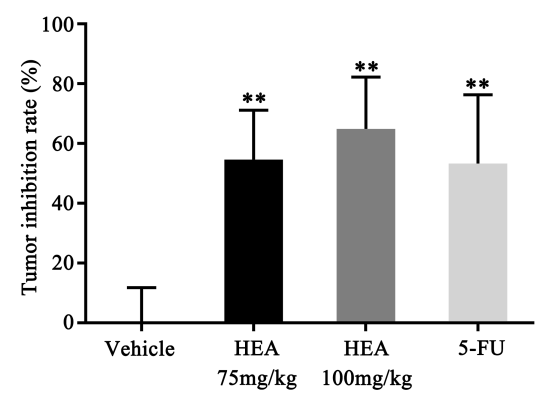

B

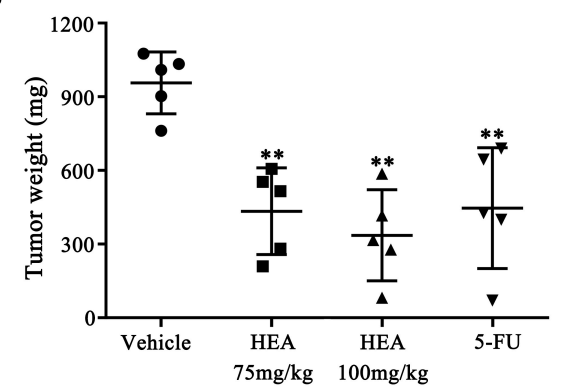

E $\quad$ H\&E

TUNEL

C
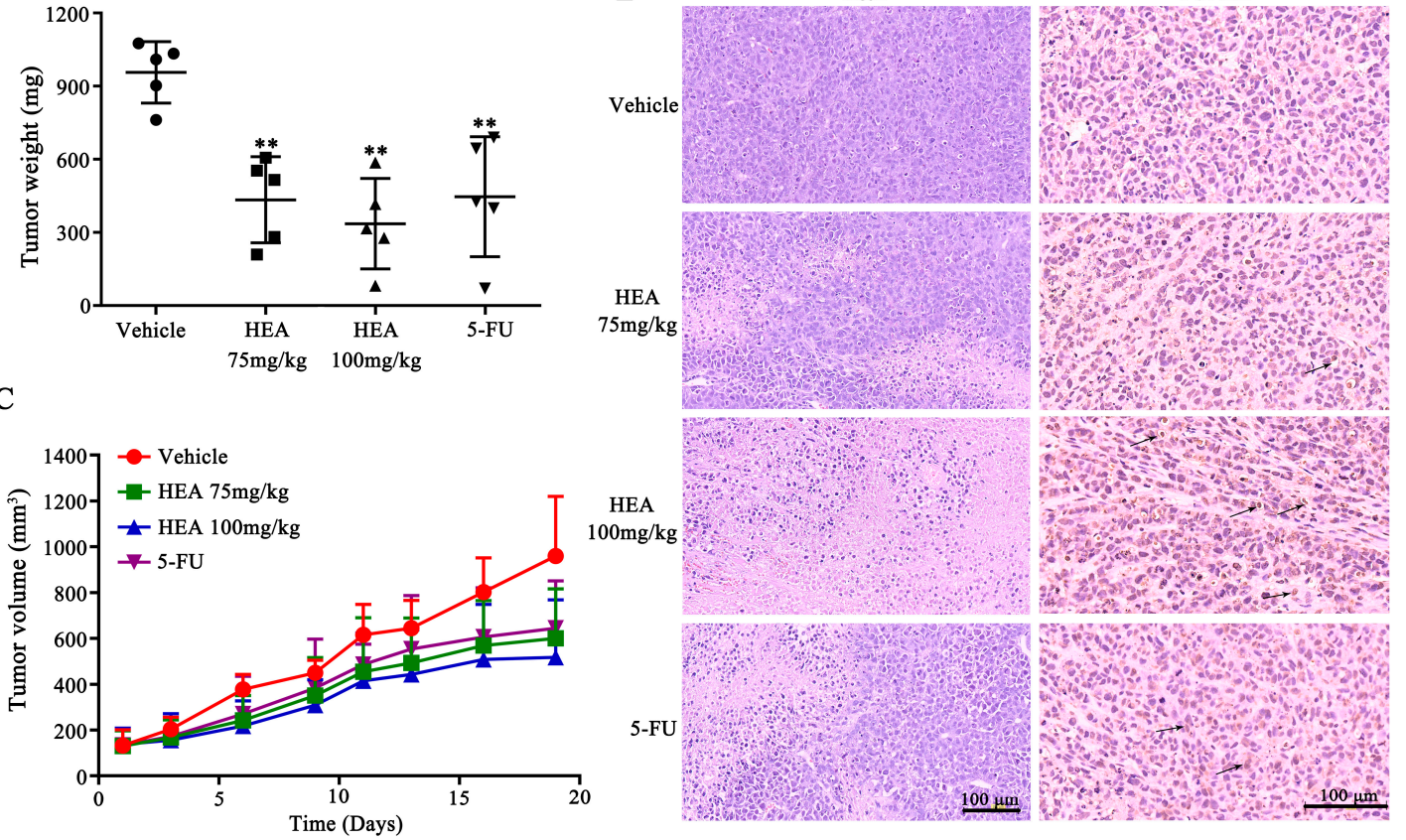

Figure 6. HEA inhibited tumor growth in the gastric carcinoma nude mouse model. (A) Morphology of the tumor xenograft resected from each nude mouse after 19 days of intragastric HEA administration. (B) Tumor weight of executed gastric carcinoma nude mouse model in each group. Data shown as mean \pm SD. (C) Tumor growth curves. Data shown as mean \pm SD (red circle: Vheicle, green square: HEA $75 \mathrm{mg} / \mathrm{kg}$, blue triangle: HEA $100 \mathrm{mg} / \mathrm{kg}$, purple triangle: 5-FU). (D) Tumor growth inhibition ratio $(\%)=(1-$ tumor weight of treatment group/control group $) \times 100 \%$. (E) H\&E and TUNEL staining of xenograft tumor tissue. Black arrows indicate TUNEL-positive cells, that is, apoptotic cells. Scale bar $=100 \mu \mathrm{m} .{ }^{* *} p<0.01$ compared with $0 \mu \mathrm{M}$ HEA group, five repeats per group.

We performed H\&E and TUNEL staining on the sections of tumors. H\&E staining indicated cell death in the tumor tissues after HEA intragastric administration, wherein a clear boundary was observed between the cell injury and noninjury tissue. In addition, TUNEL staining assay showed that TUNEL-positive cells in the HEA-treated group were significantly higher compared with those of the vehicle group. Brown staining of the tumor tissue cell nuclei after TUNEL staining was observed, indicating that apoptotic cells existed (Figure 6E). 


\section{Discussion}

Cordyceps species were verified to have antitumor activities. Both HEA and cordycepin ( $3^{\prime}$-deoxyadenosine) are main components of Cordyceps species and are also analogues of adenosine. The antitumor effect of cordycepin has been widely reported, but studies on HEA antineoplastic activity are relatively few $[6,23,24]$. Previous studies have shown that EEC has an antitumor effect, and HEA is one of the main components of EEC, but no in-depth study has been conducted [13]. In this study, we demonstrated that HEA could inhibit gastric carcinoma multiplication in vivo and in vitro and explored its mechanism for the first time.

Apoptosis is the main type of cell death when DNA damage is irreparable, and inducing the apoptosis of cancer cells has become a new direction with which to improve the antitumoral effects of cancer therapy $[25,26]$. HEA treatment resulted in apoptosis of SGC-7901 cells; however, the apoptotic rate decreased significantly after caspase inhibitor treatment (Figure 2F). Meanwhile, the expression of caspase-3, 8, 9, and 12 increased in a dose-dependent manner (Figure 2G). HEA is speculated to induce caspase-dependent apoptosis. There are two pathways in caspase-dependent cell apoptosis: the death receptor-mediated exogenous pathway and the mitochondrial-mediated endogenous pathway [27]. The common induction of apoptosis involves one of the apoptotic modes [28-30]; studies on triggering endogenous and exogenous apoptosis are widely available [31-33]. Exogenous pathways are caspase cascades triggered by the binding of death receptor Fas or TFN- $\alpha$ with its extracellular ligands. This was indeed what we detected in HEA-treated cells, where Fas, caspase-3, and caspace- 8 were significantly increased (Figure 2G). These findings suggested that HEA treatment stimulated exogenous apoptotic pathways. Meanwhile, mitochondria are the center of the endogenous pathway, and the changes in the permeability of the mitochondrial extracorporeal membrane lead to the release of cytochrome $\mathrm{C}$, which activates caspase cascade reaction [34]. Changes in mitochondrial membrane permeability in vitro are regulated by the Bcl-2 family, and p53 can regulate the transcription of Bcl-2 family $[35,36]$. In this study, the expression level of p53 was elevated, leading to the upregulation of proapoptotic protein Bax and the downregulation of antiapoptotic protein Bcl-2. Moreover, the depolarization of MMP, generation of ROS, and upregulation of cytochrome $C$ and caspase- 9 confirmed that HEA treatment accords with the endogenous apoptotic pathway. After caspase cascade reaction, PARP is cut and apoptosis is induced [37]. The downregulation of PARP and the upregulation of cleaved-PARP confirmed that apoptosis triggered by HEA treatment was involved in the two pathways of caspase-dependent apoptosis.

To bring insight into the mechanism of tumor suppression by HEA, especially in apoptosis, we examined potential targets. The flow cytometry, protein-level detection and transcriptomics showed the consistent tendency that the antitumor mechanisms of HEA were involved in ROS production, MMP depolarization, ER stress changes, and autophagy. These results reflected that HEA affected the mitochondrial homeostasis of gastric carcinoma cells. In fact, there are more and more anti-tumor studies involving multiple death pathways. Pinocembrin can induce ER stress and mitochondria-mediated apoptosis, and suppress autophagy in melanoma [38]. Oxaliplatin induces cell death via ER stress, autophagy, and ROS production in Caco-2 cells [39]. Shikonin induces apoptosis, G2/M phase arrest, and autophagy in A375 cells via the activation of ROS-mediated ER stress and p38 pathways [40]. Interaction and influence of multiple processes cause cell death. ER stress can lead to apoptosis and autophagy [41,42]. Autophagy can suppress the induction of apoptosis by inhibiting the activation of apoptosis-related caspase, thereby reducing cell damage. It can also induce apoptosis under certain circumstances. Furthermore, the activation of apoptosis-related proteins can also inhibit autophagy by degrading autophagy-related proteins [43]. In this study, both ER stress inhibitor and autophagy inhibitor decreased the apoptotic level, which confirmed that ER stress and autophagy were the two participants in HEA-induced apoptosis of gastric carcinoma cells (Figures 4D and 5C). The essence of multiprocess interaction and influence is the interaction between signal factors and signal pathways. ROS and $\mathrm{Ca}^{2+}$ overload can lead to increased MMP [44]. As one of the intensively studied oncogenes, p53 participates in cell apoptosis and cycle regulation and also activates AMPK 
to promote autophagy $[45,46]$. ER stress-induced autophagy and apoptosis also share a common upstream signaling pathway, the IRE1-JNK pathway [43]. AKT kinase phosphorylates Bcl-2 family member Bad, thereby suppressing apoptosis [47]. Moreover, AKT can also negatively regulate cell cycle through the p53/p21-dependent pathway [48]. P62 is a well-known autophagic protein, which can bind to autophagic receptor protein Atg8/LC3 and then affect cell autophagy. It can also trigger caspase cascade reaction by activating caspase- 8 to mediate apoptosis [49]. In this research, the interactions of signaling factors among ER stress-mediated and autophagy-mediated apoptosis deserves further study.

\section{Materials and Methods}

\subsection{Reagents}

DMEM and $0.25 \%$ Trypsin were purchased from HyClone (Logan, UT, USA). HEA was purchased from Solarbio (Beijing, China). FBS was obtained from Gibco (Grand Island, NY, USA). 5-FU was obtained from Sigma-Aldrich (St. Louis, MO, USA). The Annexin V-FITC/PI Apoptosis Analysis Kit was obtained from Tianjin Sungene (Tianjin, China). The Mitochondrial Membrane Potential (MMP) assay kit with JC-1, Cell Counting Kit-8 (CCK-8), Reactive Oxygen Species (ROS) assay kit, and Fluo-3 AM fluorescent probes were purchased from Beyotime (Jiangsu, China). Sodium phenylbutyrate (4-PBA) and 3-methyladenine (3-MA) were purchased from Macklin (Shanghai, China).

\subsection{Cell Culture}

Human embryonic kidney 293 (HEK293) cells, human gastric carcinoma SGC-7901 cells were purchased from Beyotime (Jiangsu, China), human gastric carcinoma AGS cells was obtained from the Cell Research Institute of the Chinese Academy of Sciences (Shanghai, China). Cells were authenticated by STR analysis and cultured in complete medium (DMEM medium containing 10\% FBS) under a humid $5 \% \mathrm{CO}_{2}$ atmosphere at $37^{\circ} \mathrm{C}$.

\subsection{Cytotoxicity Assay In Vitro}

Cytotoxicity assay in vitro was performed using CCK-8 in accordance with the manufacturer's instructions. Cells were seeded in 96-well plates (Costar Corning, Rochester, NY, USA) at a density of $5 \times 10^{3}$ cells/well. After $24 \mathrm{~h}, 200 \mu \mathrm{L}$ of DMEM medium-soluble HEA with varying dosages were added to each well, every concentration repeated in five wells. After $48 \mathrm{~h}$, the cells were incubated with $10 \mu \mathrm{L} \mathrm{CCK}-8$ at $37^{\circ} \mathrm{C}$ for $2 \mathrm{~h}$. The absorbance was measured at $450 \mathrm{~nm}\left(\mathrm{~A}_{450}\right)$ by a multimode reader (Thermo Electron Corporation, MA, USA).

\subsection{Morphological Observations}

Cells were seeded in six-well plates and then treated with varying HEA concentrations. After $48 \mathrm{~h}$, cell morphology was analyzed using an Olympus phase-contrast microscope (Olympus, Tokyo, Japan) under 20× magnification.

\subsection{Assay of Cell Apoptosis}

SGC-7901 and AGS cells were seeded in six-well plates with $1 \times 10^{5}$ cells/well and then treated with varying HEA concentrations after $24 \mathrm{~h}$. After $48 \mathrm{~h}$ of incubation, cells were harvested and rinsed and stained with Annexin V-FITC and PI. The apoptotic rate was detected by BD FACSVerse flow cytometer as previously mentioned [50]. The stained cells were observed by confocal laser scanning microscopy.

\subsection{Determination of Endogenous ROS}

We performed flow cytometry assay using $2^{\prime}, 7^{\prime}$-dichlorofluorescein-diacetate (DCFH-DA) staining to determine cellular ROS as previously described [51]. Briefly, after treatment with HEA, the cells were harvested, rinsed thrice, and incubated with $1 \mathrm{~mL}$ DCFH-DA $(10 \mu \mathrm{M})$ working solution for $20 \mathrm{~min}$ 
at $37^{\circ} \mathrm{C}$. The cells were washed thrice with DMEM to remove unbound DCFH-DA and analyzed by flow cytometry.

\subsection{Detection of $M M P$}

MMP level was detected by JC-1 probe assay kit. In cells with high MMP, J-aggregates produced red fluorescence, whereas in cells with low MMP, JC-1 monomer produced green fluorescence. The proportion of mitochondrial depolarization was measured by the ratio of red to green fluorescence. In brief, after treatment with HEA, the cells were collected and cultured with JC-1 probe $(20 \mu \mathrm{g} / \mathrm{mL})$ for $30 \mathrm{~min}$ at $37^{\circ} \mathrm{C}$. Changes in MMP were analyzed by flow cytometry.

\subsection{Intracellular $\mathrm{Ca}^{2+}$ Level Detection}

Intracellular $\mathrm{Ca}^{2+}$ was detected by Fluo-3 AM probe assay kit according to the protocol. In general, after treatment with HEA, SGC-7901 cells were collected and incubated with Fluo-3 AM probe $(5 \mu \mathrm{M})$ for $30 \mathrm{~min}$ at $37^{\circ} \mathrm{C}$. Changes in intracellular $\mathrm{Ca}^{2+}$ were analyzed using a flow cytometer.

\subsection{Transmission Electron Microscopy (TEM)}

SGC-7901 cells were treated with various doses of HEA for $48 \mathrm{~h}$ and then collected and immobilized in $2.5 \%$ glutaric dialdehyde at $4{ }^{\circ} \mathrm{C}$ overnight. After removing $2.5 \%$ glutaric dialdehyde, the samples were washed with PBS thrice and fixed with $1 \% \mathrm{H}_{2}\left[\mathrm{OsO}_{4}(\mathrm{OH})_{2}\right]$ for $2 \mathrm{~h}$. Thereafter, the samples were rinsed with PBS thrice, followed by gradient dehydration with $30 \%, 50 \%, 70 \%, 80 \%, 90 \%, 95 \%$, and $100 \%$ ethanol and acetone successively with $15 \mathrm{~min}$ at every turn. The samples were treated with Spurr embedding agent (Sigma-Aldrich, St. Louis, MO, USA) and sliced by an ultrathin slicer (Leica UC7, Wetzlar, Germany). The sections were stained in lead citrate solution and 50\% ethanol saturated solution of uranium hydrogen acetate successively and observed under a TEM (Hitachi H-7650, Tokyo, Japan).

\subsection{Western Blot Analysis}

After $48 \mathrm{~h}$ of HEA treatment, SGC-7901 cells were collected, total protein was extracted, and Western blot analysis was performed as previously described [13]. Primary rabbit antibodies against $\beta$-actin (1:3000), AIF (1:2000), Bcl-2 (1:2000), and Bax (1:2000) were purchased from HUABIO (Hangzhou, China). Primary antibodies against caspase-3 (1:2000), caspase-8 (1:2000), caspase-9 (1:2000), caspase-12 (1:1000), cytochrome C (1:500), poly(ADP-ribose) polymerase (PARP) (1:2000), cleaved-PARP (1:2000), and p53 (1:1000), were purchased from Cell Signaling Technology (Beverly, MA, USA). Primary antibodies against ATF4 (1:1000), CHOP (1:500), p62 (1:1000), and Beclin1 (1:1000) were obtained from Proteintech (Rosemont, IL, USA). Primary antibodies against LC3 (1:500), ATG5 (1:1000), and ATG12 (1:1000) were obtained from MBL (Nagoya, Japan). Anti-rabbit lgG horse-radish peroxidase-conjugated secondary antibody (1:3000) was purchased from Abcam (Cambridge, MA, USA).

\subsection{In Vivo Efficacy of HEA}

Female BALB/c nude mice (16-18 g body weight) aged 4-5 weeks were purchased from Shanghai SLAC Laboratory Animal Co., Ltd. (Shanghai, China) with production license number SCXK 2017-0005 and certificate number 20170005006588. Mice were handled in accordance with the guidelines of the National Institutes of Health (NIH). The mice were housed at the Laboratory Animal Center of Hangzhou Normal University and maintained in an SPF condition, in accordance with the animal care and use guidelines of the Organizational Animal Care and Use Committee. Approximately $2 \times 10^{6}$ cells of SGC-7901 were injected subcutaneously to establish transplanted tumor in nude mice. Two weeks after SGC-7901 cells injection, the nude mice with tumor volume of $100-150 \mathrm{~mm}^{3}$ were randomly placed into four groups (5 mice/group): the vehicle group (PBS), HEA-75 mg/kg group, HEA-100 mg/kg group, and 5-FU ( $25 \mathrm{mg} / \mathrm{kg}$ ) group. During the study, body weight and tumor volume 
were monitored twice a week in nude mice. Tumor volume was measured using a Vernier caliper and calculated using the formula $V=1 / 2$ (length $\times$ width $^{2}$ ). Each group of mice received intragastric treatment of drugs daily. After 19 days, the mice were killed via cervical dislocation, and tumors were dissected and weighted. Tumor tissue was immobilized in $4 \%$ paraformaldehyde and stained with hematoxylin and eosin (H\&E) and TUNEL.

\subsection{Statistics}

SPSS software 17.0 (SPSS Inc., Chicago, IL, USA) and GraphPad Prism 6.0 (GraphPad, San Diego, CA, USA) were used for statistical analysis. One-way ANOVA and t-tests were used to evaluate the statistical significance. Data were expressed as means \pm SDs.

\section{Conclusions}

This study proved for the first time that HEA had anti-gastric carcinoma activity in vitro and in vivo. HEA played an anti-tumor role by promoting apoptosis of human gastric carcinoma cells in vitro. Further studies showed that HEA could induce ROS production and MMP depolarization to promote the apoptosis of gastric carcinoma cells. Meanwhile, we found that HEA-induced autophagy and ER stress also played proapoptotic roles. In vivo studies also revealed that HEA could also significantly inhibit the growth of tumors in nude mice and induce the apoptosis of tumor tissues. These results together demonstrated the anticancer effect of HEA, suggesting that HEA is a promising chemotherapeutic agent for gastric carcinoma.

Supplementary Materials: Supplementary materials can be found at http://www.mdpi.com/1422-0067/21/16/ 5815/s1.

Author Contributions: Conceptualization, X.L. and X.J.; data curation, W.Y. and L.Y.; funding acquisition, L.S.; investigation, C.L.; methodology, H.X. and M.G.; project administration, L.S.; resources, M.G. and L.S.; writing —original draft, H.X., X.L., and Y.C.; writing—review and editing, H.X. and Z.S. All authors have read and agreed to the published version of the manuscript.

Funding: This work was supported by grants from the National Natural Science Foundation of China (31572462 and 31272375).

Acknowledgments: Chao Sun (Analysis Center of Agrobiology and Environmental Sciences, Zhejiang University) is appreciated for providing help with flow cytometry.

Conflicts of Interest: The authors declare no conflict of interest.

\section{Abbreviations}

$\begin{array}{ll}\text { 3-MA } & \text { 3-methyladenine } \\ \text { 4-PBA } & \text { Sodium phenylbutyrate } \\ \text { CCK-8 } & \text { Cell Counting Kit-8 } \\ \text { DCFH-DA } & 2^{\prime}, 7^{\prime} \text {-dichlorofluorescein-diacetate } \\ \text { DMEM } & \text { Dulbecco's modified Eagle's medium } \\ \text { EEC } & \text { Ethanolic extract of Cordyceps cicadae } \\ \text { ER } & \text { Endoplasmic reticulum; FBS, Fetal bovine serum } \\ \text { FITC } & \text { Fluorescein isothiocyanate } \\ \text { HEA } & \text { N6-(2-Hydroxyethyl)-adenosine } \\ \text { H\&E } & \text { Hematoxylin-eosin } \\ \text { JC-1 } & 5,5^{\prime}, 6,6^{\prime} \text {-Tetrachloro-1, } 1^{\prime}, 3,3^{\prime} \text {-tetraethyl-imidacarbocyanine iodide } \\ \text { MMP } & \text { Mitochondrial membrane potential } \\ \text { PI } & \text { Propidium iodide } \\ \text { ROS } & \text { Reactive oxygen species } \\ \text { TEM } & \text { Transmission electron microscopy }\end{array}$




\section{References}

1. Ferlay, J.; Soerjomataram, I.; Dikshit, R.; Eser, S.; Mathers, C.; Rebelo, M.; Parkin, D.M.; Forman, D.; Bray, F. Cancer incidence and mortality worldwide: Sources, methods and major patterns in GLOBOCAN 2012. Int. J. Cancer 2015, 136, E359-E386. [CrossRef] [PubMed]

2. Allemani, C.; Matsuda, T.; Di Carlo, V.; Harewood, R.; Matz, M.; Niksic, M.; Bonaventure, A.; Valkov, M.; Johnson, C.J.; Esteve, J.; et al. Global surveillance of trends in cancer survival 2000-14 (CONCORD-3): Analysis of individual records for 37513025 patients diagnosed with one of 18 cancers from 322 population-based registries in 71 countries. Lancet 2018, 391, 1023-1075. [CrossRef]

3. Macdonald, J.S.; Smalley, S.R.; Benedetti, J.; Hundahl, S.A.; Estes, N.C.; Stemmermann, G.N.; Haller, D.G.; Ajani, J.A.; Gunderson, L.L.; Jessup, J.M.; et al. Chemoradiotherapy after surgery compared with surgery alone for adenocarcinoma of the stomach or gastroesophageal junction. N. Engl. J. Med. 2001, 345, 725-730. [CrossRef] [PubMed]

4. Chua, Y.J.; Cunningham, D. The UK NCRI MAGIC trial of perioperative chemotherapy in resectable gastric cancer: Implications for clinical practice. Ann. Surg. Oncol. 2007, 14, 2687-2690. [CrossRef] [PubMed]

5. Kuo, Y.-C.; Sun, C.-M.; Tsai, W.J.; Ou, J.-C.; Chen, W.-P.; Lin, C.-Y. Chinese herbs as modulators of human mesangial cell proliferation: Preliminary studies. J. Lab. Clin. Med. 1998, 132, 76-85. [CrossRef]

6. Zhang, Z.; Tudi, T.; Liu, Y.; Zhou, S.; Feng, N.; Yang, Y.; Tang, C.; Tang, Q.-J.; Zhang, J. Preparative isolation of cordycepin, N-6-(2-hydroxyethyl)-adenosine and adenosine from Cordyceps militaris by macroporous resin and purification by recycling high-speed counter-current chromatography. J. Chromatogr. B 2016, 1033, 218-225. [CrossRef]

7. Qu, G.R.; Geng, M.W.; Han, S.H.; Zhang, Z.G.; Xue, F. Microwave-assisted green and efficient synthesis of N-6-(2-Hydroxyethyl) adenosine and its analogues. Chin. Chem. Lett. 2006, 17, 1149-1151.

8. Wang, X.; Qin, A.; Xiao, F.; Olatunji, O.J.; Zhang, S.; Pan, D.; Han, W.; Wang, D.; Ni, Y. N6-(2-hydroxyethyl)-adenosine from Cordyceps cicadae protects against diabetic kidney disease via alleviation of oxidative stress and inflammation. J. Food. Biochem. 2018, 43, e12727. [CrossRef]

9. Meng, Z.; Kang, J.; Wen, T.-C.; Lei, B.; Hyde, K.D. Cordycepin and N6-(2-Hydroxyethyl)-adenosine from Cordyceps pruinosa and their interaction with human serum albumin. PLoS ONE 2015, 10, e0121669. [CrossRef]

10. Lu, M.-Y.; Chen, C.-C.; Lee, L.-Y.; Lin, T.-W.; Kuo, C.-F. N6-(2-Hydroxyethyl) adenosine in the medicinal mushroom Cordyceps cicadae attenuates lipopolysaccharide-stimulated pro-inflammatory responses by suppressing TLR4-mediated NF-кB signaling pathways. J. Nat. Prod. 2015, 78, 2452-2460. [CrossRef]

11. Zhu, W.; Chai, Y.; Jin, Y.; Li, X.; Yu, X. Effects of antinocieptive compound from Ophiocordyceps sobolifera on the transcriptome and Adora1 etc. pain-related genes in gouty rats. Mygosystema 2017, 36, 48-59.

12. Peng, X.; Chai, Y.; Zhu, B.; Jin, Y.; Li, X.; Yu, L. The protective effects of N 6-(2-hydroxyethyl)-adenosine extracted from Ophiocordyceps sobolifera on renal ischemia reperfusion injury (IRI) in mice. Mygosystema 2015, 34, 311-320.

13. Xie, H.; Li, X.; Chen, Y.; Lang, M.; Shen, Z.; Shi, L. Ethanolic extract of Cordyceps cicadae exerts antitumor effect on human gastric cancer SGC-7901 cells by inducing apoptosis, cell cycle arrest and endoplasmic reticulum stress. J. Ethnopharmacol. 2019, 231, 230-240. [CrossRef] [PubMed]

14. Zhang, Z.; Zhou, S.; Liu, Y.; Zhang, J.; Zhu, L.; Feng, N.; Tang, Q. Isolation and purification of cordycepin and N 6-(2-hydroxyethyl)-adenosine from Cordyceps militaris fruit bodies by high speed counter-current chromatography. Mygosystema 2016, 35, 742-749.

15. Pikarsky, E.; Porat, R.M.; Stein, I.; Abramovitch, R.; Amit, S.; Kasem, S.; Gutkovich-Pyest, E.; Urieli-Shoval, S.; Galun, E.; Ben-Neriah, Y. NF-kB functions as a tumour promoter in inflammation-associated cancer. Nature 2004, 431, 461-466. [CrossRef]

16. Yang, G.; Yang, X. Smad4-mediated TGF-beta signaling in tumorigenesis. Int. J. Biol. Sci. 2010, 6, 1-8. [CrossRef]

17. Zheng, R.; Zhu, R.; Li, X.; Li, X.; Shen, L.; Chen, Y.; Zhong, Y.; Deng, Y. N6-(2-Hydroxyethyl) adenosine from Cordyceps cicadae ameliorates renal interstitial fibrosis and prevents inflammation via TGF- $\beta 1 / \mathrm{Smad}$ and NF-кB signaling pathway. Front. Physiol. 2018, 9, 1229. [CrossRef]

18. Tang, S.-A.; Zhou, Q.; Guo, W.-Z.; Qiu, Y.; Wang, R.; Jin, M.; Zhang, W.; Li, K.; Yamori, T.; Dan, S.; et al. In vitro antitumor activity of stellettin $\mathrm{B}$, a triterpene from marine sponge Jaspis stellifera, on human glioblastoma cancer SF295 cells. Mar. Drugs 2014, 12, 4200-4213. [CrossRef] 
19. Sinha, K.; Das, J.; Pal, P.B.; Sil, P.C. Oxidative stress: The mitochondria-dependent and mitochondria-independent pathways of apoptosis. Arch. Toxicol. 2013, 87, 1157-1180. [CrossRef]

20. Ly, J.D.; Grubb, D.R.; Lawen, A. The mitochondrial membrane potential (Delta psi m) in apoptosis; an update. Apoptosis 2003, 8, 115-128. [CrossRef]

21. Rubinstein, A.D.; Eisenstein, M.; Ber, Y.; Bialik, S.; Kimchi, A. The autophagy protein ATG12 associates with antiapoptotic Bcl-2 family members to promote mitochondrial apoptosis. Mol. Cell 2011, 44, 698-709. [CrossRef] [PubMed]

22. Erlich, S.; Mizrachy, L.; Segev, O.; Lindenboim, L.; Zmira, O.; Adi-Harel, S.; Hirsch, J.A.; Stein, R.; Pinkas-Kramarski, R. Differential interactions between Beclin 1 and Bcl-2 family members. Autophagy 2007, 3, 561-568. [CrossRef] [PubMed]

23. Bi, Y.; Li, H.; Yi, D.; Bai, Y.; Zhong, S.; Liu, Q.; Chen, Y.; Zhao, G. $\beta$-catenin contributes to cordycepin-induced MGMT inhibition and reduction of temozolomide resistance in glioma cells by increasing intracellular reactive oxygen species. Cancer Lett. 2018, 435, 66-79. [CrossRef] [PubMed]

24. Qin, P.; Li, X.; Yang, H.; Wang, Z.; Lu, D. Therapeutic potential and biological applications of cordycepin and metabolic mechanisms in cordycepin-producing fungi. Molecules 2019, 24, 2231. [CrossRef] [PubMed]

25. Chitikova, Z.V.; Gordeev, S.A.; Bykova, T.V.; Zubova, S.G.; A Pospelov, V.; Pospelova, T.V. Sustained activation of DNA damage response in irradiated apoptosis-resistant cells induces reversible senescence associated with mTOR downregulation and expression of stem cell markers. Cell Cycle 2014, 13, 1424-1439. [CrossRef]

26. Kerr, J.; Winterford, C.M.; Harmon, B.V. Apoptosis-its significance in cancer and cancer-therapy. Cancer 1994, 73, 2013-2026. [CrossRef]

27. Chang, K.C.; Unsinger, J.; Davis, C.G.; Schwulst, S.J.; Muenzer, J.T.; Strasser, A.; Hotchkiss, R.S. Multiple triggers of cell death in sepsis: Death receptor and mitochondrial-mediated apoptosis. FASEB J. 2007, 21, 708-719. [CrossRef]

28. Ma, Z.; Lu, L.; Yang, J.-J.; Wang, X.-X.; Su, G.; Wang, Z.-L.; Chen, G.-H.; Sun, H.-M.; Wang, M.-Y.; Yang, Y. Lariciresinol induces apoptosis in HepG2 cells via mitochondrial-mediated apoptosis pathway. Eur. J. Pharmacol. 2018, 821, 1-10. [CrossRef]

29. Zhang, R.; Yi, R.; Bi, Y.; Xing, L.; Bao, J.; Li, J. The effect of selenium on the Cd-induced apoptosis via NO-mediated mitochondrial apoptosis pathway in chicken liver. Boil. Trace Element Res. 2017, 178, 310-319. [CrossRef]

30. Ji, Y.; Yu, M.; Qi, Z.; Cui, D.; Xin, G.; Wang, B.; Jia, W.; Chang, L. Study on apoptosis effect of human breast cancer cell MCF-7 induced by lycorine hydrochloride via death receptor pathway. Saudi Pharm. J. 2017, 25, 633-637. [CrossRef]

31. Yin, J.; Ni, B.; Liao, W.-G.; Gao, Y.-Q. Hypoxia-induced apoptosis of mouse spermatocytes is mediated by HIF-1 through a death receptor pathway and a mitochondrial pathway. J. Cell Physiol. 2018, 233, 1146-1155. [CrossRef] [PubMed]

32. Zhao, H.; He, Y.; Li, S.; Sun, X.; Wang, Y.; Shao, Y.; Hou, Z.; Xing, M. Subchronic arsenism-induced oxidative stress and inflammation contribute to apoptosis through mitochondrial and death receptor dependent pathways in chicken immune organs. Oncotarget 2017, 8, 40327-40344. [CrossRef] [PubMed]

33. Huang, T.-C.; Chiu, P.-R.; Chang, W.-T.; Hsieh, B.-S.; Huang, Y.-C.; Cheng, H.-L.; Huang, L.-W.; Hu, Y.-C.; Chang, K.-L. Epirubicin induces apoptosis in osteoblasts through death-receptor and mitochondrial pathways. Apoptosis 2018, 23, 226-236. [CrossRef] [PubMed]

34. Chen, Q.; Chai, Y.-C.; Mazumder, S.; Jiang, C.; Macklis, R.M.; Chisolm, G.M.; Almasan, A. The late increase in intracellular free radical oxygen species during apoptosis is associated with cytochrome c release, caspase activation, and mitochondrial dysfunction. Cell Death Differ. 2003, 10, 323-334. [CrossRef]

35. Harris, M.H.; Thompson, C.B. The role of the Bcl-2 family in the regulation of outer mitochondrial membrane permeability. Cell Death Differ. 2000, 7, 1182-1191. [CrossRef]

36. Pietrzak, M.; Puzianowska-Kuznicka, M. p53-dependent repression of the human MCL-1 gene encoding an anti-apoptotic member of the BCL-2 family: The role of Sp1 and of basic transcription factor binding sites in the MCL-1 promoter. Boil. Chem. 2008, 389, 383-393. [CrossRef]

37. Bressenot, A.; Marchal, S.; Bezdetnaya, L.; Garrier, J.; Guillemin, F.; Plénat, F. Assessment of apoptosis by immunohistochemistry to active caspase-3, active caspase-7, or cleaved PARP in monolayer cells and spheroid and subcutaneous Xenografts of human carcinoma. J. Histochem. Cytochem. 2008, 57, 289-300. [CrossRef] 
38. Zheng, Y.; Wang, K.; Wu, Y.; Chen, Y.; Chen, X.; Hu, C.W.; Chen, Y.-F. Pinocembrin induces ER stress mediated apoptosis and suppresses autophagy in melanoma cells. Cancer Lett. 2018, 431, 31-42. [CrossRef]

39. Shi, Y.; Tang, B.; Yu, P.-W.; Tang, B.; Hao, Y.-X.; Lei, X.; Luo, H.-X.; Zeng, D.-Z. Autophagy protects against Oxaliplatin-induced cell death via ER stress and ROS in Caco-2 cells. PLoS ONE 2012, 7, e51076. [CrossRef]

40. Liu, Y.; Kang, X.; Niu, G.; He, S.; Zhang, T.; Bai, Y.; Li, Y.; Hao, H.; Chen, C.; Shou, Z.; et al. Shikonin induces apoptosis and prosurvival autophagy in human melanoma A375 cells via ROS-mediated ER stress and p38 pathways. Artif. Cells Nanomed. Biotechnol. 2019, 47, 626-635. [CrossRef]

41. Ogata, M.; Hino, S.-I.; Saito, A.; Morikawa, K.; Kondo, S.; Kanemoto, S.; Murakami, T.; Taniguchi, M.; Tanii, I.; Yoshinaga, K.; et al. Autophagy is activated for cell survival after endoplasmic reticulum stress. Mol. Cell Biol. 2006, 26, 9220-9231. [CrossRef] [PubMed]

42. Rao, R.V.; Hermel, E.; Castro-Obregon, S.; Del Rio, G.; Ellerby, L.M.; Ellerby, H.M.; Bredesen, D.E. Coupling endoplasmic reticulum stress to the cell death program-Mechanism of caspase activation. J. Biol. Chem. 2001, 276, 33869-33874. [CrossRef]

43. Song, S.; Tan, J.; Miao, Y.; Li, M.; Zhang, Q. Crosstalk of autophagy and apoptosis: Involvement of the dual role of autophagy under ER stress. J. Cell Physiol. 2017, 232, 2977-2984. [CrossRef] [PubMed]

44. Kim, K.-Y.; Cho, H.-J.; Yu, S.-N.; Kim, S.-H.; Yu, H.-S.; Park, Y.-M.; Mirkheshti, N.; Kim, S.Y.; Song, C.S.; Chatterjee, B.; et al. Interplay of reactive oxygen species, intracellular $\mathrm{Ca}^{2+}$ and mitochondrial homeostasis in the apoptosis of prostate cancer cells by deoxypodophyllotoxin. J. Cell Biochem. 2013, 114, 1124-1134. [CrossRef]

45. Li, T.; Kon, N.; Jiang, L.; Tan, M.; Ludwig, T.; Zhao, Y.; Baer, R.; Gu, W. Tumor suppression in the absence of p53-mediated cell-cycle arrest, apoptosis, and senescence. Cell 2012, 149, 1269-1283. [CrossRef] [PubMed]

46. Crighton, D.; Wilkinson, S.; O’Prey, J.; Syed, N.; Smith, P.; Harrison, P.R.; Gasco, M.; Garrone, O.; Crook, T.; Ryan, K.M. DRAM, a p53-induced modulator of autophagy, is critical for apoptosis. Cell 2006, 126, 121-134. [CrossRef]

47. Franke, T.F.; Hornik, C.P.; Segev, L.; A Shostak, G.; Sugimoto, C. PI3K/Akt and apoptosis: Size matters. Oncogene 2003, 22, 8983-8998. [CrossRef]

48. Miyauchi, H.; Minamino, T.; Tateno, K.; Kunieda, T.; Toko, H.; Komuro, I. Akt negatively regulates the in vitro lifespan of human endothelial cells via a p53/p21-dependent pathway. EMBO J. 2004, 23, 212-220. [CrossRef]

49. Moscat, J.; Diaz-Meco, M.T. P62 at the crossroads of autophagy, apoptosis, and cancer. Cell 2009, 137, 1001-1004. [CrossRef]

50. Chen, Y.; Jiang, X.; Xie, H.; Li, X.; Shi, L. Structural characterization and antitumor activity of a polysaccharide from Ramulus mori. Carbohydr. Polym. 2018, 190, 232-239. [CrossRef]

51. Li, X.; Xie, H.; Chen, Y.; Lang, M.; Chen, Y.-Y.; Shi, L. Silkworm pupa protein hydrolysate induces mitochondria-dependent apoptosis and $\mathrm{S}$ phase cell cycle arrest in human gastric cancer SGC-7901 cells. Int. J. Mol. Sci. 2018, 19, 1013. [CrossRef] [PubMed]

(C) 2020 by the authors. Licensee MDPI, Basel, Switzerland. This article is an open access article distributed under the terms and conditions of the Creative Commons Attribution (CC BY) license (http://creativecommons.org/licenses/by/4.0/). 